\title{
Marine-derived collagen biomaterials from echinoderm connective tissues
}

\author{
Cinzia Ferrario a, Livio Leggio ${ }^{a}$, Roberta Leone ${ }^{a}{ }^{c}$, Cristiano Di Benedetto ${ }^{d}$, \\ Luca Guidetti ${ }^{a, c}$, Valentina Coccè ${ }^{b}$, Miriam Ascagni ${ }^{a}$, Francesco Bonasoro ${ }^{a, c}$,

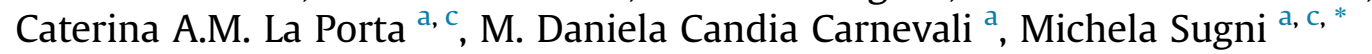 \\ a Department of Biosciences, University of Milan, Via Celoria, 26, 20133, Milan, Italy \\ ${ }^{\mathrm{b}}$ Fondazione IRCCS Cà Granda Ospedale Maggiore Policlinico, Maxillofacial and Dental Unit, Department of Biomedical, Surgical and Dental Sciences, \\ University of Milan, Via Commenda, 10, 20122, Milan, Italy \\ ${ }^{\mathrm{c}}$ Center for Complexity and Biosystems, University of Milan, Via Celoria, 16, 20133, Milan, Italy \\ ${ }^{\mathrm{d}}$ King Abdullah University of Science and Technology (KAUST), Biological and Environmental Sciences and Engineering (BESE), Thuwal, 23955-6900, Saudi \\ Arabia
}

\section{A R T I C L E I N F O}

\section{Article history:}

Received 9 December 2015

Received in revised form 19 March 2016

Accepted 29 March 2016

Available online $\mathrm{xxx}$

\section{Keywords:}

"Blue" biotechnology

Alternative biomaterial

Marine collagen

Echinoderms

Mutable collagenous tissues

Human fibroblast culture

Guided tissue regeneration

Environmental impact

By-product valorisation

\begin{abstract}
A B S T R A C T
The use of marine collagens is a hot topic in the field of tissue engineering. Echinoderms possess unique connective tissues (Mutable Collagenous Tissues, MCTs) which can represent an innovative source of collagen to develop collagen barrier-membranes for Guided Tissue Regeneration (GTR). In the present work we used MCTs from different echinoderm models (sea urchin, starfish and sea cucumber) to produce echinoderm-derived collagen membranes (EDCMs). Commercial membranes for GTR or soluble/ reassembled (fibrillar) bovine collagen substrates were used as controls. The three EDCMs were similar among each other in terms of structure and mechanical performances and were much thinner and mechanically more resistant than the commercial membranes. Number of fibroblasts seeded on seaurchin membranes were comparable to the bovine collagen substrates. Cell morphology on all EDCMs was similar to that of structurally comparable (reassembled) bovine collagen substrates. Overall, echinoderms, and sea urchins particularly, are alternative collagen sources to produce efficient GTR membranes. Sea urchins display a further advantage in terms of eco-sustainability by recycling tissues from food wastes.
\end{abstract}

() 2016 Elsevier Ltd. All rights reserved.

\section{Introduction}

The marine ecosystem and its inhabitants have always been sources of food, biomaterials, active compounds or simply ideas for human applications (e.g. medicine, cosmetics, biotechnology, biofuels, etc.). Many examples of sustainable exploitation of "blue resources" have been reported so far including: i) professional

\footnotetext{
* Corresponding author. Department of Biosciences, University of Milan, Via Celoria, 26, 20133, Milan, Italy.

E-mail addresses: cinzia.ferrario@unimi.it (C. Ferrario), livio.leggio@gmail.com (L. Leggio), roberta.leone1986@gmail.com (R. Leone), cristiano.dibenedetto1@ gmail.com (C. Di Benedetto), luca.guidetti@outlook.com (L. Guidetti), 82. valentina@libero.it (V. Coccè), miriam.ascagni@unimi.it (M. Ascagni), francesco. bonasoro@unimi.it (F. Bonasoro), caterina.laporta@unimi.it (C.A.M. La Porta), daniela.candia@unimi.it (M.D. Candia Carnevali), michela.sugni@unimi.it (M. Sugni).
}

swimsuits inspired by shark skin, ii) algae and marine sponge bioactive substances (Gupta and Abu-Ghannam, 2011; Dembitsky et al., 2005; Rao et al., 2006; Guzmán et al., 2011) for pharmacological use (anti-cancer or anti-neurodegeneration drugs), iii) structural molecules (i.e. chitin and collagen) from different marine animals as alternative biomaterials for biomedical applications (Gomez d'Ayala et al., 2008; Gómez-Guillén et al., 2011). Basic research on ocean life and applied research on possible industrial applications are the key activities in terms of "blue growth" in biotechnology and bioeconomy (European Commission, 2012): the sustainable exploitation of "blue resources" and the eco-friendly management of industrial wastes are nowadays two of the most challenging aspects in this field.

To date, marine invertebrates (e.g. sponges, jellyfish and molluscs), are among the most promising groups of animals for this kind of studies because of their variety and abundance in all seas. 
However, a wide range of marine biodiversity is still unexplored from this point of view. Echinoderms are marine invertebrates widespread in all the oceans and employed as source of food for decades (e.g. sea cucumbers and sea urchins; Conand, 2004; Barrington et al., 2009). They are well-known also for their peculiar connective tissues, called Mutable Collagenous Tissues or MCTs, which are able to rapidly change their passive mechanical properties (stiffness and viscosity), under the nervous system control (Wilkie, 2005). MCTs are a unique feature of echinoderms and, although their presence was not described in all known species, their ubiquity throughout the Phylum is highly probable: indeed, MCTs have been described in all the five extant Classes (Wilkie, 2005) and in fossil specimens as well (Baumiller and Ausich, 1996), thus indicating they are probably an ancestral character. This type of tissue has been recently proposed as possible source of inspiration for "smart dynamic biomaterials" for tissue engineering and regenerative medicine applications (Barbaglio et al., 2012, 2013). Particularly, the sea urchin peristomial membrane (a wellknown MCT) has been proposed as a sustainable and eco-friendly source of native fibrillar collagen to produce thin membranes for regenerative medicine applications (Di Benedetto et al., 2014). Indeed, the peristomial membrane is a sea urchin food industry waste that can be transformed in a highly valuable by-product.

Among the "blue biomaterials" marine collagen has the most promising perspectives as valid candidate for replacing the most commonly used mammal-derived collagen. This latter is routinely employed in a wide range of human applications (Karim and Bath, 2008; Silva et al., 2014; Silvipriya et al., 2015), from large-scale uses, such as food (Djagny et al., 2010), pharmaceutical/nutraceutical industry (Sahithi et al., 2013) and cosmetics (Buck II et al., 2009), to more targeted fields, such as cell cultures (Lee et al., 2008) and biomedical/clinical applications (Tsai et al., 2005; Glowacki and Mizuno, 2008). However, due to allergy problems (Silvipriya et al., 2015), religious and social/life style constraints (Jenkins et al., 2010), disease transmission-connected reasons (e.g. bovine spongiform encephalopathy or BSE) and high costs of recombinant technologies, collagen sources alternative to mammals are constantly investigated (Silva et al., 2014).

In this sense marine animals, and echinoderms in particular, are surely appealing (Shimomura et al., 1962; Nagai and Suzuki, 2000; Nagai et al., 2000; Swatschek et al., 2002; Song et al., 2006; UriarteMontoya et al., 2010; Barros et al., 2014; Di Benedetto et al., 2014). A further advantage of echinoderm MCTs is the relative easiness to obtain high amount of native collagen fibrils, which maintain their original structure (Matsumura, 1974; Trotter et al., 1994; Di Benedetto et al., 2014). Indeed, most mammalian collagen is usually employed in its hydrolized (acid-solubilized) form, a characteristic that strongly reduces the mechanical performances of the produced membrane/scaffold and that can be a limit in those biomedical applications where highly resistant materials, with fibril three-dimensional organization, are required e.g. tendon/ligament regeneration (Kew et al., 2011) or dermis re-construction (Ruszczak, 2003). Echinoderm MCTs can be useful to easily and rapidly produce fibrillar collagen membranes with a high similarity in terms of both ultrastructural and mechanical characteristics to the physiological situation of connective tissue.

A specific regenerative medicine field where fibrillar collagen membranes are commercially used is Guided Tissue Regeneration (GTR; Ferreira et al., 2012; Tal et al., 2012). One of the aims of GTR is to reduce post-surgical tissue adhesions, a common and only partially solved complication (Parker et al., 2001), which prevents proper tissue regeneration. These latter are abnormal attachments or mixture of cells forming between tissues or organs after surgery or due to local inflammation. Only recently researchers have tried to produce effective and satisfactory tools to overcome them.
Indeed, barrier-membranes composed by several different biomaterials (e.g. chitosan and hyaluronic acid) have been tested for GTR but none of them displayed all the necessary functional properties, the most important of which is avoiding cell penetration into the underlying anatomical compartment (Tang et al., 2007). Collagen-based membranes seem promising from this point of view because their porosity/three-dimensional structure can be modified as desired. However, their use is still limited by the weak mechanical resistance. This, for example, reduces their efficacy in prevention of wound dehiscence or in tendon repair.

The present work was addressed to evaluate if echinodermderived collagen membranes could represent a valuable "blue alternative" to the commercially available (mammal-derived) membranes employed for GTR. This was done by considering different aspects, including ultrastructural properties, mechanical performances as well as the behaviour of human skin-derived fibroblasts (hSDFs) when seeded on these substrate types. Considering the high biodiversity of echinoderms, we also evaluated which animal/MCT source might be more suitable for this biotechnological application. To accomplish this, representatives of different echinoderm Classes were used: the sea urchin Paracentrotus lividus, the starfish Echinaster sepositus and the sea cucumber Holothuria tubulosa.

\section{Materials and methods}

\subsection{Experimental animals}

Adult specimens of the sea urchin P. lividus, the starfish E. sepositus and the sea cucumber $H$. tubulosa were collected by SCUBA divers in Paraggi (Marine Protected Area of Portofino, Ligurian Sea, Italy), transferred to the Department of Biosciences (University of Milan) and immediately dissected. Samples of sea urchin peristomial membranes (PM; Fig. 1A and B), starfish aboral arm walls (AW; Fig. 1C and D) and sea cucumber whole body walls (BW; Fig. $1 \mathrm{E}-\mathrm{G}$ ) were collected and stored at $-20{ }^{\circ} \mathrm{C}$ for the subsequent collagen extraction protocol (see paragraph 2.2). Animal collection and experimental manipulation were performed according to the Italian law.

\subsection{Echinoderm collagen extraction}

Sea urchin collagen was extracted from the peristomial membranes as previously described by Di Benedetto et al. (2014). Starfish aboral arm walls followed the same protocol with only slight modifications. Briefly, the frozen tissues of both animals were dissected in small pieces, rinsed in artificial sea water and left in a hypotonic buffer (10 mM Tris, 0.1\% EDTA) for $12 \mathrm{~h}$ at room temperature (RT) and then in a decellularizing solution (10 mM Tris, $0.1 \%$ Sodium Dodecyl Sulphate) for $12 \mathrm{~h}$ at RT. After several washings in phosphate-buffered saline (PBS), samples were placed in disaggregating solution ( $0.5 \mathrm{M} \mathrm{NaCl}, 0.1 \mathrm{M}$ Tris- $\mathrm{HCl} \mathrm{pH} \mathrm{8.0,0.1} \mathrm{M} \beta$ mercaptoethanol, $0.05 \mathrm{M}$ EDTA-Na). The obtained collagen suspension was filtered and dialysed against 0.5 M EDTA-Na solution (pH 8.0) for $3 \mathrm{~h}$ at $\mathrm{RT}$ and against $\mathrm{dH}_{2} \mathrm{O}$ overnight at RT. Starfish samples underwent an additional step in $1 \mathrm{mM}$ citric acid (pH 3-4) between decellularizing and disaggregating solutions in order to remove as much as possible the calcium carbonate ossicles present in the fresh tissue. All the steps were carried out under stirring conditions.

Sea cucumber collagen was extracted from the whole body wall following a different protocol. Briefly, the starting tissue was cut into small pieces, placed in PBS and gentamicin $(40 \mu \mathrm{g} / \mathrm{mL})$ and left in stirring conditions at RT for at least 5 days in order to obtain a collagen suspension that was subsequently filtered. Suspensions 

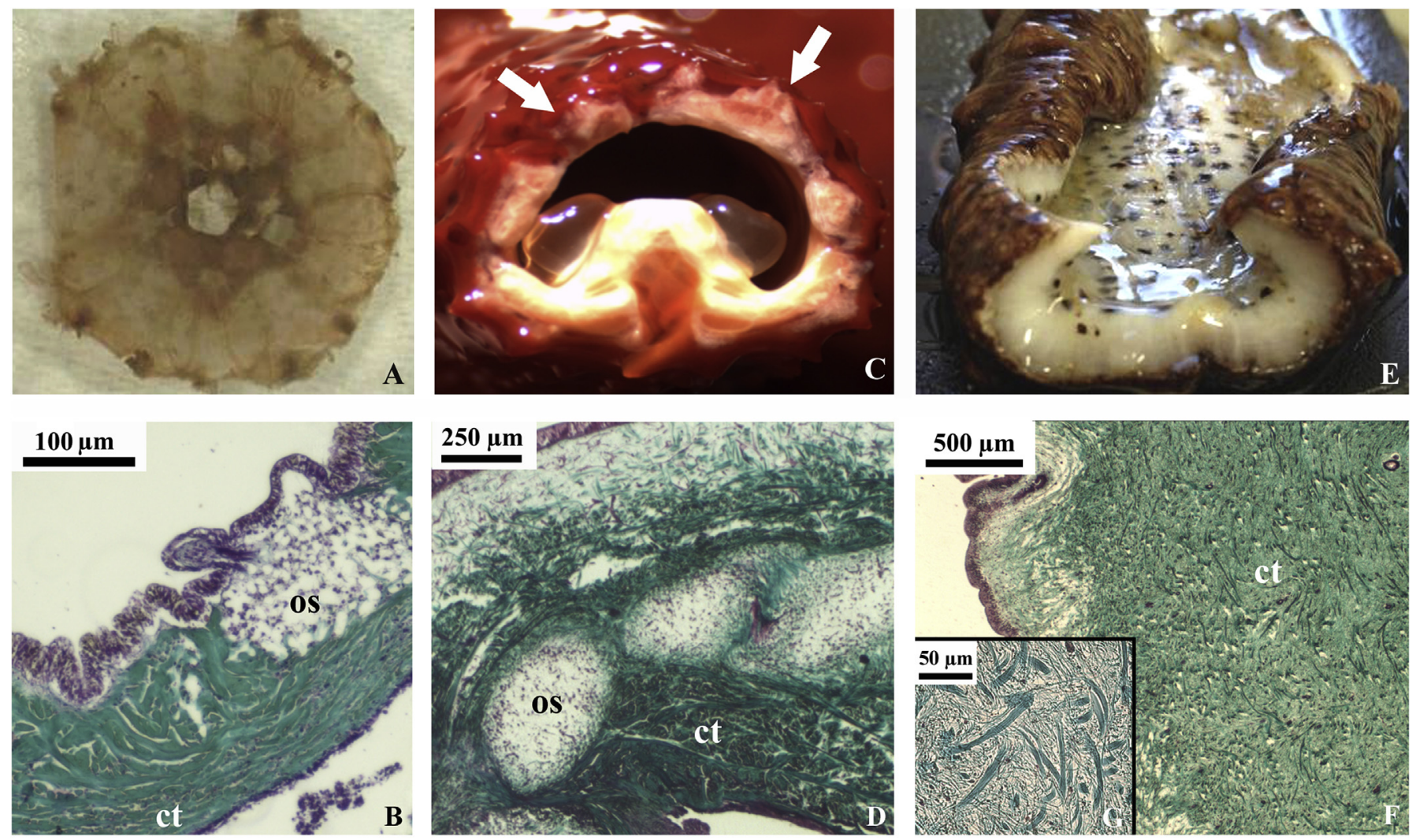

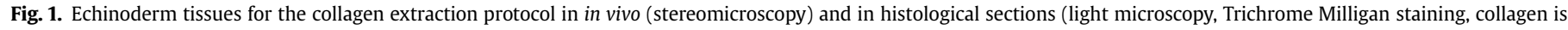

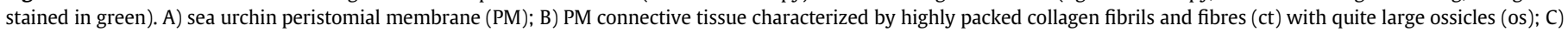

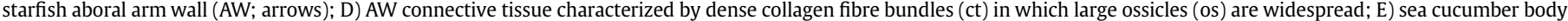
wall (BW); F) BW connective tissue with small spicules and absence of highly packed collagen fibres (ct); G) detail of F on the loosely packed collagen fibrils.

obtained from the three experimental models were then stored at $-80^{\circ} \mathrm{C}$ until use.

\subsection{Ultrastructural characterization of isolated echinoderm collagen fibrils}

\subsubsection{D-period measurements}

A drop of fibril suspension was placed on a 300 mesh copper grid with FORMVAR membrane. The excess was removed after 5 min and the grid was stained with potassium phosphotungstate ( $\mathrm{pH} 7.3$ ) for $1 \mathrm{~min}$. All the grids were then observed and photographed under a transmission electron microscope (TEM JEOL SX 100 , Tokyo, Japan) and the D-period was measured from digital images by Adobe Photoshop CS3 Extended Software (Version 10.0.1).

\subsubsection{Glycosaminoglycan (GAG) visualization}

A $10 \mu \mathrm{L}$ drop of suspension of each type of collagen was added to FORMVAR-coated grids which, after excess removal, were processed according to the following steps: filtered $\mathrm{dH}_{2} \mathrm{O}(30 \mathrm{~s} \times 3)$, $500 \mathrm{mM} \mathrm{NaC1}$ (1 min), fixative solution (2.5\% glutaraldehyde, $300 \mathrm{mM} \mathrm{MgCl} 2,25 \mathrm{mM}$ sodium acetate, $\mathrm{pH} \mathrm{5.6;1} \mathrm{min}), 0.2 \%$ Cuprolinic Blue ( $1 \mathrm{~min})$, fixative solution $(30 \mathrm{~s} \times 2$ ), $1 \%$ sodium tungstate $(1 \mathrm{~min})$ and filtered $\mathrm{dH}_{2} \mathrm{O}(30 \mathrm{~s} \times 3)$. The grids were then observed and photographed under a transmission electron microscope (TEM JEOL SX 100, Tokyo, Japan).

\subsection{Production of echinoderm-derived collagen membrane (EDCM)}

Membranes of the three echinoderm collagen types were prepared as previously described for sea urchin membrane by Di Benedetto et al. (2014) to produce substrates for both mechanical and in vitro tests (see paragraphs 2.5 .2 and 2.6 respectively). Briefly, $500 \mu \mathrm{L}$ of the collagen suspensions were dried overnight in a silicon mould at $+37^{\circ} \mathrm{C}$. The resulting collagen sheets were weighted in order to calculate the original collagen concentrations. The remaining suspensions were centrifuged for $10 \mathrm{~min}$ at $50 \times \mathrm{g}$ to remove eventual precipitated debris and then for $20 \mathrm{~min}$ at $2000 \times$ $\mathrm{g}$ (sea urchin), $1500 \times \mathrm{g}$ (starfish) or $4000 \times \mathrm{g}$ (sea cucumber). The pellet was re-suspended in $0.01 \%$ TritonX-100 for cell culture substrates or in autoclaved filtered $\mathrm{dH}_{2} \mathrm{O}$ for membranes for mechanical tests to reach a $2 \mathrm{mg} / \mathrm{mL}$ final collagen concentration. $300 \mu \mathrm{L}$ of the former suspensions were placed in $24 \times$ multiwells dishes and $800 \mu \mathrm{L}$ of the latter in rubber silicone moulds $(10 \mathrm{~mm} \times 16 \mathrm{~mm})$ and left dry overnight at $+37{ }^{\circ} \mathrm{C}$. The obtained collagen membranes were then immersed in EDC/NHS (1-ethyl-3-(3dimethylaminopropyl)carbodiimide/N-hydroxysuccinimide) cross-linker solution (30 mM EDC/15 mM NHS in 100 mM MES (2(N-morpholino)ethanesulfonic acid) buffer, pH 5.5; Song et al., 2006; Yang, 2012) for $4 \mathrm{~h}$ at RT and then washed with PBS, $\mathrm{dH}_{2} \mathrm{O}$ and $70 \% \mathrm{EtOH}$.

\subsection{Collagen membrane characterization}

2.5.1. Ultrastructural analysis: scanning electron microscopy (SEM)

Collagen membranes for both cell cultures and mechanical tests 
were fixed with $2 \%$ glutaraldehyde in $0.1 \mathrm{M}$ cacodylate buffer $\left(2 \mathrm{~h},+4{ }^{\circ} \mathrm{C}\right.$ ) and post-fixed with $1 \%$ osmium tetroxide in $0.1 \mathrm{M}$ sodium cacodylate buffer ( $2 \mathrm{~h}, \mathrm{RT})$. After careful washings with $\mathrm{dH}_{2} \mathrm{O}$, samples were dehydrated with an increasing concentration ethanol and then transferred to a series of solutions of hexamethyldisilazane (HMDS)/absolute ethanol in different proportions (1:3, 1:1, 3:1 and 100\% HMDS). Membranes were then mounted on stubs, covered with pure gold (Agar SEM Auto Sputter, Stansted, UK) and observed under a scanning electron microscope (LEO1430, Zeiss, Oberkochen, Germany). Measurements of collagen membrane thickness, mesh size (superficial porosity), fibril diameter and length were performed with Adobe Photoshop CS3 Extended Software. SEM analyses were carried out also on both reassembled (fibrillar) bovine collagen (BCMs; see paragraph 2.6) and commercial membranes (CMs; bovine collagen) in order to compare their ultrastructural characteristics with the EDCM ones.

\subsubsection{Mechanical analysis: force-extension tests}

Echinoderm and commercial collagen membranes were cut into small strips ( $2 \mathrm{~mm} \times 10 \mathrm{~mm}$ ) whose ends were fixed to rigid plastic supports with cyanoacrylate cement (Superattak ${ }^{\mathbb{R}}$, Heckel, Düsseldorf, Germany). Each strip was photographed under a LEICA MZ75 stereomicroscope provided with a Leica EC3 Camera and Leica Application Suite LAS EZ Software (Version 1.8.0) to allow digital width measurements. For details on the experimental apparatus and conditions see Di Benedetto et al. (2014).

19, 21, 46 and 7 strips were tested for sea urchin, starfish, sea cucumber-derived and commercial membranes respectively. Samples were immersed in L-15 Leibovitz cell culture medium throughout the mechanical test. They were subjected to elongations of $0.1 \mathrm{~mm}$ every $10 \mathrm{~s}$ until complete rupture. The force peaks generated at each elongation step were used to produce a stress-strain curve from which the mechanical parameters (stiffness, tensile strength and tensile strain) were calculated as follows:

$\Delta$ stress $(\mathrm{MPa})=\Delta \mathrm{F} / \mathrm{CSA}($ Cross Section Area $)$;

$\Delta$ strain $=\Delta \mathrm{l} / \mathrm{l}($ sample starting length $)$

Stiffness (Young's Modulus; MPa $)=\Delta$ stress $/ \Delta$ strain;

Tensile strength $(\mathrm{MPa})=$ Maximum weight before rupture/CSA;

Tensile strain $(\%)=$ Extension/l (sample starting length) $\times 100$.

\subsection{In vitro tests}

Primary human dermal fibroblasts (hSDFs) derived from human epithelial biopsy were obtained as described in Coccè et al. (2016). Briefly, the cells were cultured in minimum essential medium Eagle (EMEM) with Earles salts and $\mathrm{NaHCO}_{3}$ (Sigma-Aldrich) supplemented with $10 \%$ fetal calf serum (Euroclone), $2 \mathrm{mM}$ glutamine (cod. ECB3004D, Euroclone), antibiotic antimycotic solution $100 \mathrm{U} /$ $\mathrm{mL}$ penicillin, $100 \mu \mathrm{g} / \mathrm{mL}$ streptomycin and $0.25 \mu \mathrm{g} / \mathrm{mL}$ amphotericin B (Sigma-Aldrich). Cells were seeded in $24 \times$ multiwells on EDCMs as well as on reassembled (fibrillar) bovine collagen membranes (BCMs), on bovine skin-derived soluble collagen (Sigma-Aldrich) and on plastic as controls, the last two being the commonly used controls for in in vitro tests. $300 \mu \mathrm{L}$ of bovine-skin derived soluble collagen (Sigma-Aldrich) was added to each well, left for 15 min and subsequently removed and left air dried for at least $2 \mathrm{~h}$ before use. This same soluble collagen was used to produce BCMs: 8 volumes of collagen mixed with 1 volume of PBS $10 \times$ and 1 volume of $0.1 \mathrm{M} \mathrm{NaOH}$ were added in each well and left to dry overnight at $+37^{\circ} \mathrm{C}$ before use. In vitro tests lasted 4 days.

\subsubsection{Cell counting}

Cells seeded on the different substrates were fixed in $4 \%$ paraformaldehyde in PBS, stained with $0.1 \%$ methylene blue and carefully washed with filtered $\mathrm{dH}_{2} \mathrm{O}$. Photographs of five representative areas for each well were taken under a LEICA MZ75 stereomicroscope provided with a Leica EC3 Camera and Leica Application Suite LAS EZ Software (Version 1.8.0). Cell counting was independently performed from digital images by two different operators. Once absence of statistically significant differences between operators was verified ( $t$-test), mean values were considered. The mean cell number of each well was normalized against the mean cell number of the control (plastic) wells and expressed as a percentage. Each treatment (= substrate) was repeated in duplicates or triplicates. Experiments were repeated five times (rounds).

\subsubsection{Cell morphology and cell-substrate adhesion/interaction analysis}

SEM and immunofluorescence (IF) techniques were performed to analyse cell morphology as well as cell-substrate adhesion and interactions. For SEM analyses cell seeded substrates were fixed after 4 days in $2 \%$ glutaraldehyde in $0.1 \mathrm{M}$ sodium cacodylate buffer for $2 \mathrm{~h}\left(+4{ }^{\circ} \mathrm{C}\right)$ and then processed as previously described (see paragraph 2.5.1). Samples were observed under a scanning electron microscope (LEO-1430, Zeiss, Oberkochen, Germany).

IF specific stainings were performed to reveal cytoskeletal Factin organisation and both stress fibre and focal adhesion presence. After 4 days in culture, cells were fixed in $4 \%$ paraformaldehyde and permeabilised with $0.1 \%$ Triton X-100 in PBS for 30 min at RT. Cells were subsequently blocked with $10 \%$ normal goat serum in PBS for $1 \mathrm{~h}$ and incubated with mouse monoclonal Anti-Vinculin antibody (1:500, Sigma-Aldrich) overnight at $+4{ }^{\circ} \mathrm{C}$. Then, cells were incubated with FITC (fluorescein isothiocyanate) conjugated goat anti-mouse secondary antibody (1:250, Millipore) and Actin-stain 555 phalloidin ( $100 \mathrm{nM}$, Cytoskeleton) for $1 \mathrm{~h}$. Nuclei were counterstained with Fluoroshield with DAPI $(4,6-$ diamine-2-phenylindole dihydrochloride, Sigma-Aldrich). Samples were then examined under a Leica TCS SP2 Laser Scanning Confocal microscope (Leica Microsystems).

\subsection{Statistical analyses}

For mechanical tests non-parametric Kruskal-Wallis test, Tukey's test and Dunn's Multiple Comparison test were used to analyse stiffness, tensile strength and tensile strain of both EDCMs and commercial membranes (GraphPad Software).

For in vitro tests Generalised Linear Model (GLM) was used to analyse the effect of both substrate type and round on cell number with Bonferroni post-hoc test (SPSS 15.0 Version Software). In both cases, differences were considered significant at the $P<0.05$ level (see Results).

\section{Results}

\subsection{Echinoderm-derived collagen extraction}

The extraction protocols optimized for the different echinoderm tissues (i.e. sea urchin peristomial membrane, starfish aboral arm wall and sea cucumber body wall) allowed us to obtain highly concentrated collagen fibril suspensions. No fibril aggregates, cell 
debris and calcium carbonate residues were detected from both light and electron microscopy observations, thus they were considered suitable for the production of two-dimensional membranes (Fig. 2). Sea urchin-derived collagen was extracted from both animals collected in the wild and from commercial activities (e.g. waste from restaurants) but since ultrastructural, mechanical and in vitro analyses showed almost identical results (data not shown) they were pooled together.

\subsection{Ultrastructural characterization of collagen fibrils and membranes}

Table 1 summarizes the mean fibril D-period for each type of collagen membrane. As shown in Fig. 3, in all three echinoderm collagen types GAGs were present regularly distributed along the whole fibril, strictly according to the D-patterning.

As for TEM analyses, also SEM observations confirmed the "cleanliness" of the echinoderm-derived collagen suspensions since no debris and undissociated fibres were detected (Fig. 2). Data on fibril ultrastructural features and on membrane average mesh size and thickness are reported in Table 1. SEM analyses showed that in both EDCMs and BCMs, collagen fibrils were randomly distributed on the well plastic surface, without a clearly organized pattern and creating a highly dense collagen network (Fig. 2). Differently, commercial membranes showed thick fibril/fibre bundles interspersed in a loose thin fibril network and displayed a more oriented distribution (Fig. 2B and C). Fig. 4 shows at a macroscopical level (stereomicroscopy) an example of commercial bovine collagen membrane and an example of EDCM (sea urchinderived collagen membrane).

\subsection{Mechanical characterization of echinoderm-derived and commercial collagen membranes}

Stiffness (or Young's Modulus), tensile strength and tensile strain were evaluated in order to have a complete overview and comparison among the EDCM and commercial membrane mechanical features in physiological conditions (i.e. immersed in a fluid biochemically and osmotically similar to that present in human tissues). Both EDCM stiffness (Fig. 5) and tensile strength (Fig. 6) were significantly higher ( 20 folds) than those of commercial membrane, which, on the contrary, showed higher tensile strain comparing to EDCMs. Sea urchin membrane stiffness (see also Di Benedetto et al., 2014) was similar to that of both starfish and sea cucumber membranes $(P>0.05$; Dunn's Multiple Comparison Test), whereas sea cucumber membrane stiffness was significantly higher than that of starfish membrane $(P<0.001$; Dunn's Multiple Comparison Test). Both sea urchin and sea cucumber membrane stiffness was significantly higher than that of commercial membrane $(P<0.01$ and $P<0.001$ respectively; Dunn's Multiple Comparison Test), whereas starfish membrane stiffness was statistically similar to commercial membrane values $(P>0.05$; Dunn's Multiple Comparison Test). Echinoderm membrane tensile strength was statistically similar among each type of collagen $(P>0.05$; Dunn's Multiple Comparison Test) and significantly higher than that of commercial membrane $(P<0.01$ sea urchin, $P<0.001$ starfish and sea cucumber; Dunn's Multiple Comparison Test). Commercial membrane mean tensile strain \pm SD $(62.12 \% \pm 14.43)$ was higher than that of EDCMs (sea urchin: $32.81 \% \pm 5.77$ (see also Di Benedetto et al., 2014); starfish: $49.48 \% \pm 20.89$; sea cucumber: $27.96 \% \pm 9.89$ ).
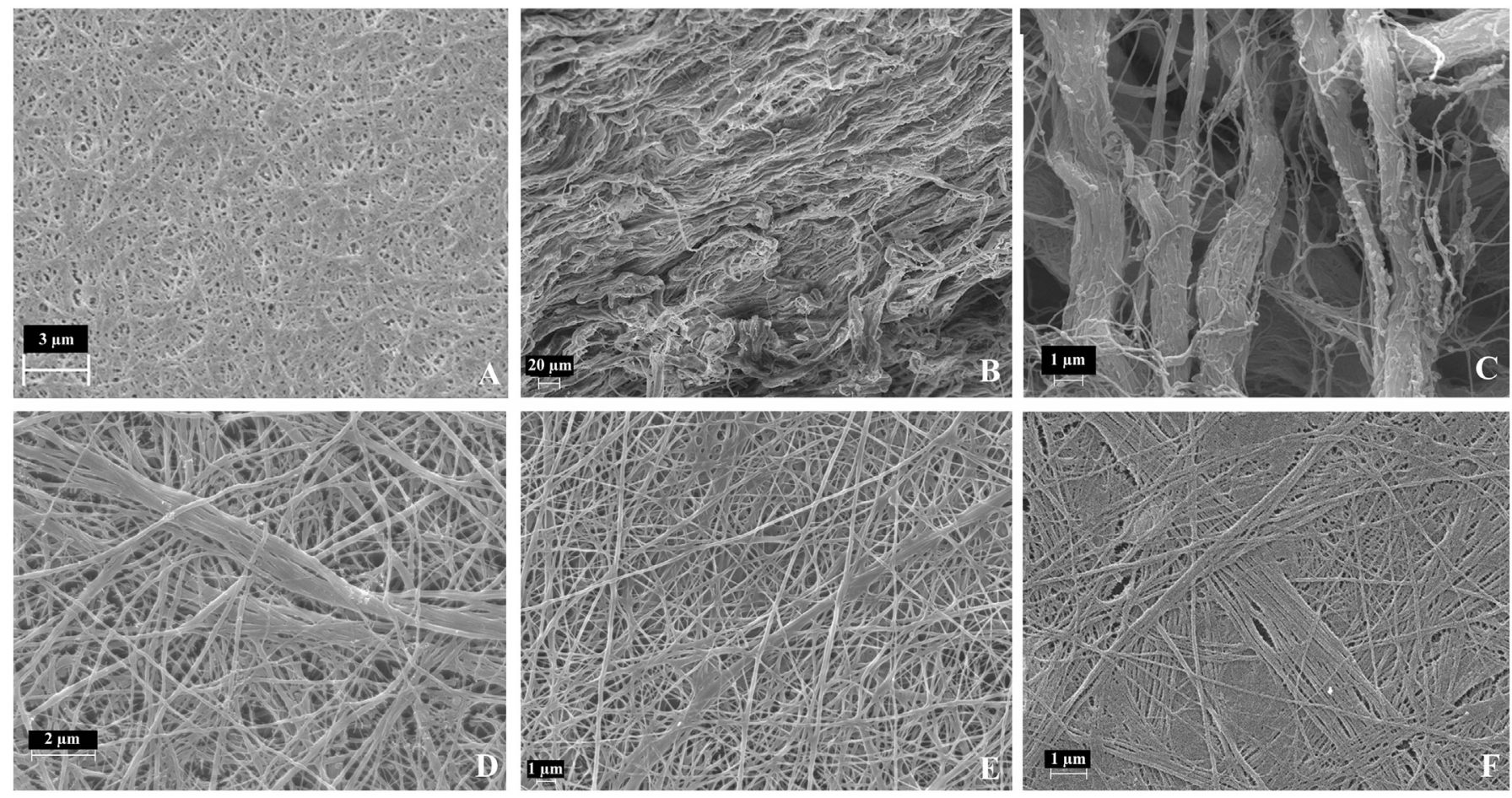

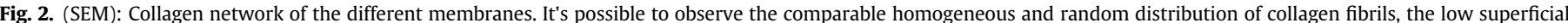

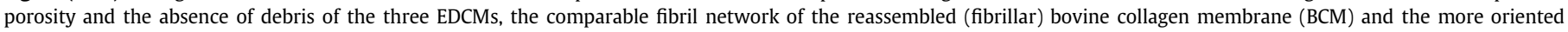

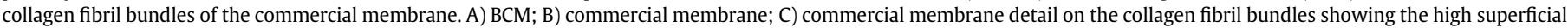
porosity of the collagen network; D) sea urchin-derived collagen membrane; E) starfish-derived collagen membrane; F) sea cucumber-derived collagen membrane. 
Table 1

Ultrastructural features of collagen fibrils and membranes. Data shown as mean \pm SD and/or ranges.

\begin{tabular}{|c|c|c|c|c|}
\hline & Commercial membrane (CM) & $\begin{array}{l}\text { Sea urchin } \\
\text { P. lividus }\end{array}$ & $\begin{array}{l}\text { Starfish } \\
\text { E. sepositus }\end{array}$ & $\begin{array}{l}\text { Sea cucumber } \\
\text { H. tubulosa }\end{array}$ \\
\hline Mean fibril D-period $(\mathrm{nm}) \pm \mathrm{SD}$ & - & $62.7 \pm 2.8$ & $63 \pm 4.7$ & $66 \pm 1.6$ \\
\hline Fibril D-period range (nm) & - & $60-66^{\mathrm{a}}$ & $60-70$ & $61.4-68.9$ \\
\hline Diameter range (nm) & $\begin{array}{l}70-3640 \\
\text { (fibrils and fibres) }\end{array}$ & $\begin{array}{l}25-300^{\mathrm{b}} \\
\text { (fibrils) }\end{array}$ & 37-362 (fibrils) & $\begin{array}{l}36-520 \\
\text { (fibrils) }\end{array}$ \\
\hline Mean length $(\mu \mathrm{m}) \pm \mathrm{SD}$ & - & $208 \pm 93.3$ & $337.7 \pm 106.8$ & $233 \pm 115.8$ \\
\hline Average mesh size $(\mu \mathrm{m})$ & $>>2$ & $<2^{\mathrm{b}}$ & $<2$ & $<2$ \\
\hline Membrane thickness range $(\mu \mathrm{m})$ & $316-390$ & $9-14$ & $9-15$ & $10-11$ \\
\hline
\end{tabular}

a Tricarico et al., 2012.

b Di Benedetto et al., 2014.

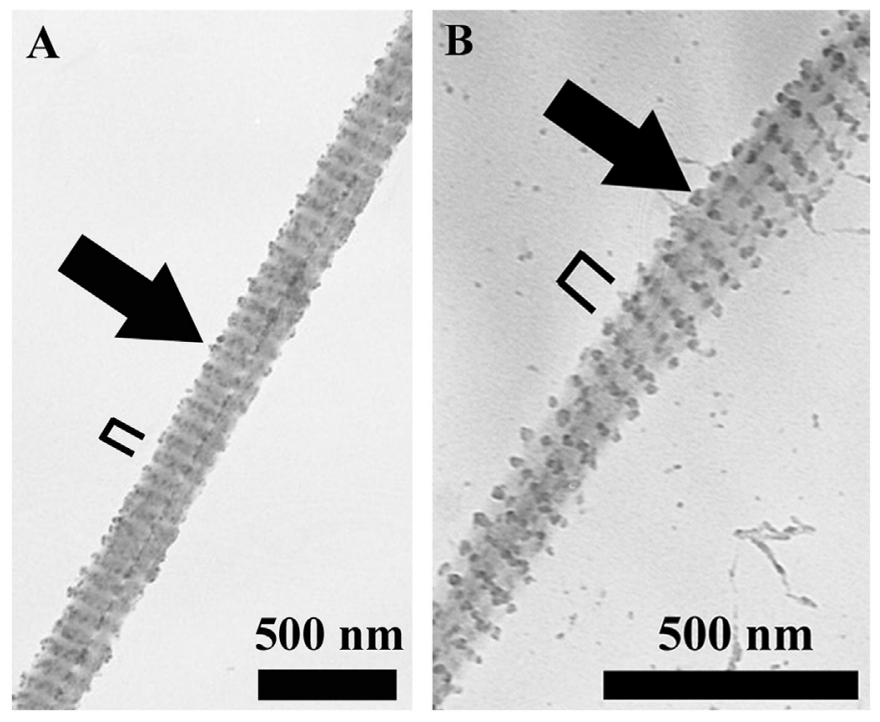

Fig. 3. (TEM): GAG distribution (arrows) on echinoderm collagen fibril surface according to the D-patterning (square brackets). A) starfish-derived collagen fibril; B) sea cucumber-derived collagen fibril. For GAG decoration on sea urchin-derived collagen fibril see Fig. 2 in Di Benedetto et al., 2014.

\subsection{Cell counting}

The Generalised Linear Model (GLM) was used to evaluate the effect of substrate type, experimental round and their interaction on the number of seeded cells. Cell growth was significantly affected by both factors $(\mathrm{P}<0.001)$ but not by their interaction $(P=0.079)$. This means that, during the same experimental round, changing the substrate, cells grew differently, and that, with the same substrate, cell grew differently in different experimental rounds depending on the specific condition of each experimental round. However, the statistical evaluation of the interaction between substrate type and experimental round indicates the substrate performance (from the most favourable to the least one in relation to the cell growth) did not significantly change in the different experimental rounds. Data on cell counting are reported in Fig. 7 and Table A (Appendices). Cell number on sea urchinderived collagen was significantly higher than that on the other echinoderm-derived substrates (starfish $P<0.001$ and sea cucumber $P<0.022$ ) but was comparable to the control (plastic, $100 \%$ ) and was also statistically similar to soluble bovine-skin collagen substrate $(P>0.05)$; however, hSDFs were less numerous than on BCMs, even if only in one round. Cell percentage on starfish and sea cucumber-derived membranes was comparable $(P>0.05)$ but significantly lower than all the other substrate types $(P<0.05)$. Moreover, hSDFs were seeded once also on aligned type I collagen
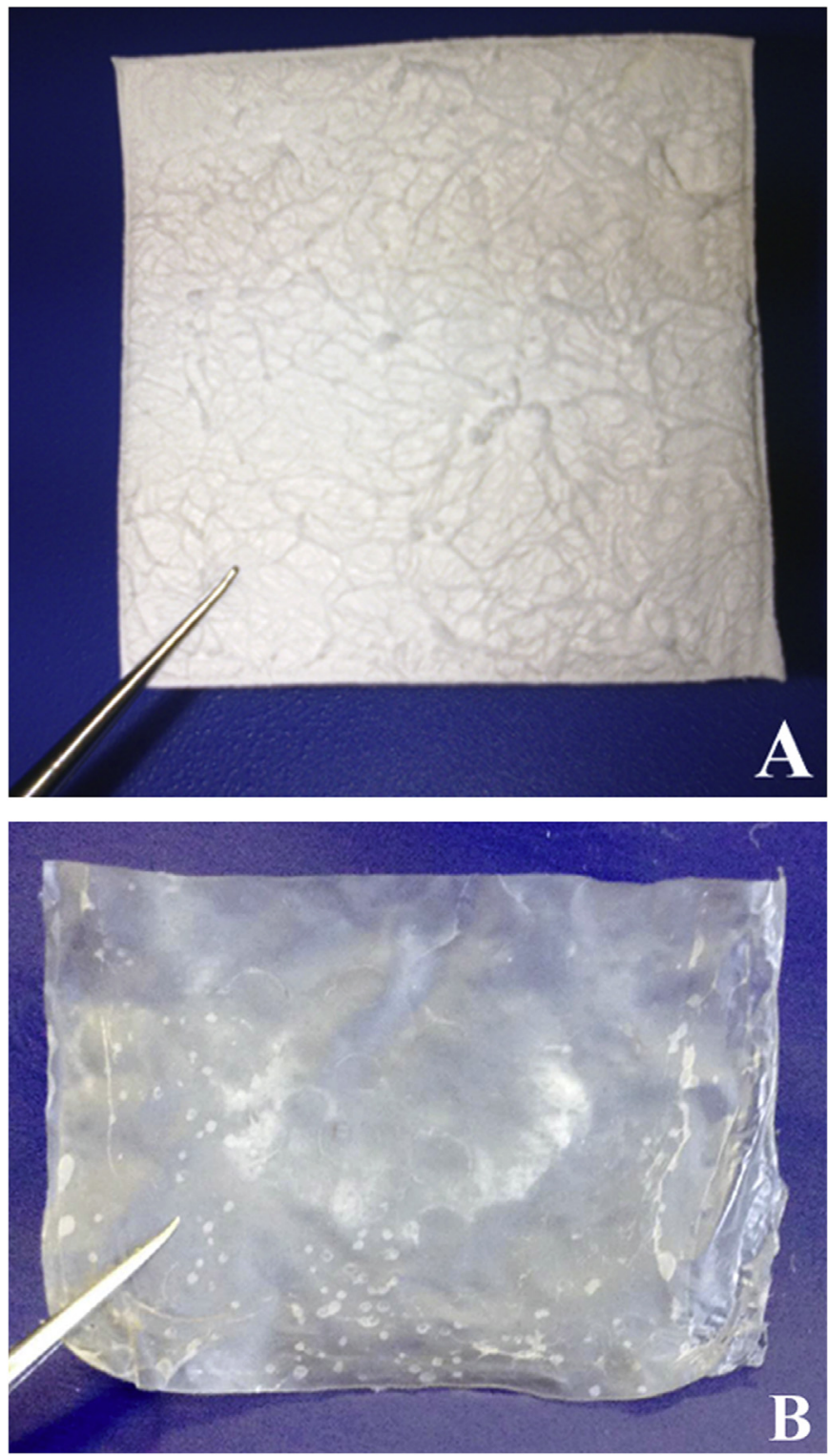

Fig. 4. (Stereomicroscopy): Examples of the collagen membranes. A) commercial membrane currently available for clinical purposes; B) sea urchin-derived collagen membrane after the cross-linking protocol.

fibrils (AlignCol ${ }^{\circledR}$ Matrix, Sigma-Aldrich) and the percentage of cells (normalized against the plastic) resulted comparable $(81.63 \% \pm 8.13)$ to that of cells seeded on EDCMs. 


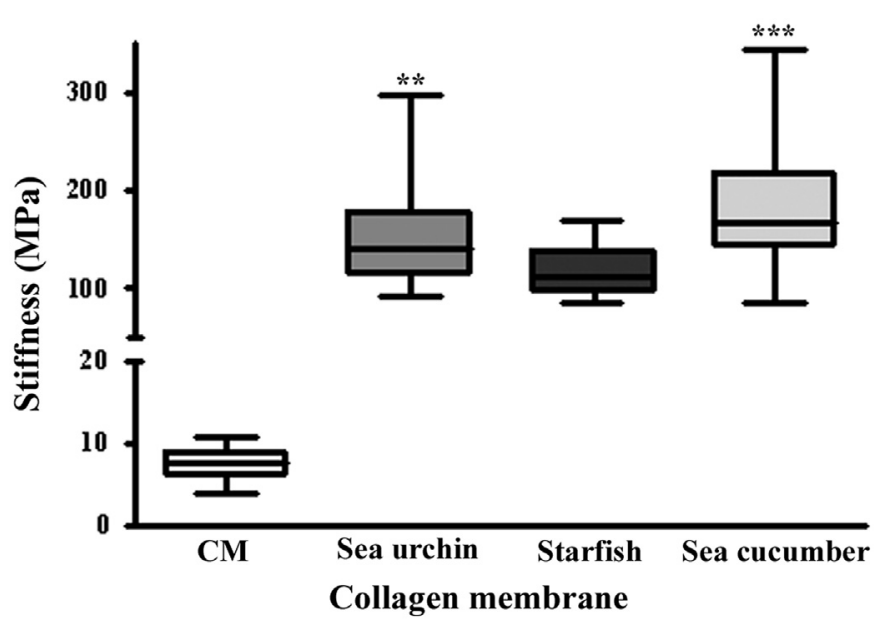

Fig. 5. Box plot of stiffness (or Young's Modulus) of commercial membranes and EDCMs. CM, commercial membrane $(n=7)$; sea urchin-derived collagen membrane ( $n=19)$; starfish-derived collagen membrane $(n=21)$; sea cucumber-derived collagen membrane $(n=47) .{ }^{* *} P<0.01,{ }^{* * *} P<0.001$ vs commercial membrane (Dunn's Multiple Comparison Test).

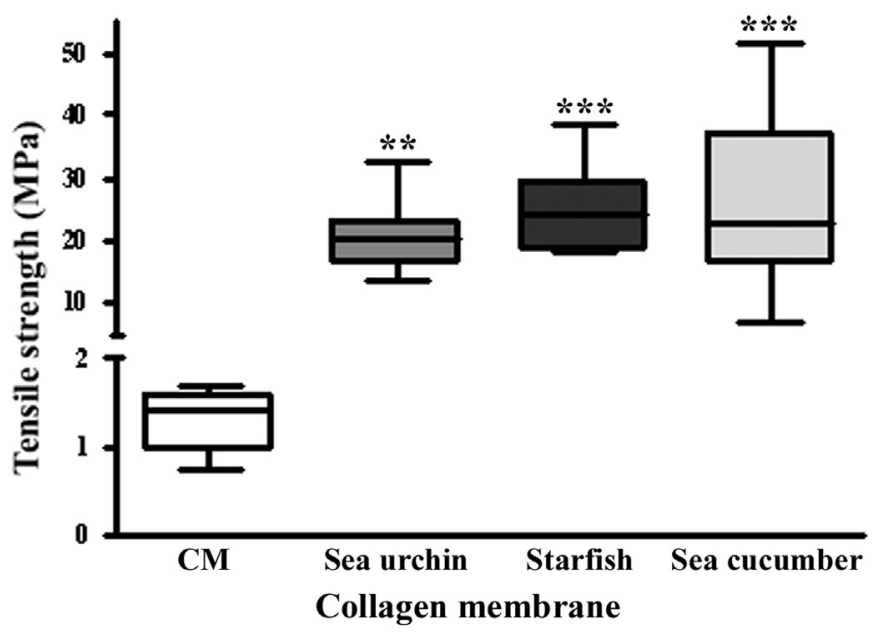

Fig. 6. Box plot of tensile strength of commercial membranes and EDCMs. CM, commercial membrane $(n=7)$; sea urchin-derived collagen membrane $(n=19)$; starfishderived collagen membrane $(n=21)$; sea cucumber-derived collagen membrane ( $n=47) .{ }^{* *} P<0.01,{ }^{* * *} P<0.001$ vs commercial membrane (Dunn's Multiple Comparison Test).

\subsection{Cell morphology and cell-substrate adhesion/interactions}

Overall, hSDFs seeded on fibrillar substrates, namely EDCMs and reassembled bovine collagen membranes (BCMs; Fig. 8C) presented a more elongated shape in comparison to those on "flat" substrates, as plastic and soluble bovine collagen, where they showed a highly flattened "sun-like" morphology (Fig. 8).

Considering cell-substrate interactions (Fig. 9), fibroblasts seeded on both EDCMs and BCMs similarly displayed a low number of short filopodial processes, which strongly localized only at the main cell attachment points (usually two), whereas cells on "flat" substrates (plastic and soluble bovine collagen) showed a higher number of numerous, long and thin filopodial processes, widespread on the whole cell surface.

Immunofluorescence microscopy (IF) confirmed the different cell morphology already observed by SEM analyses and enabled visualisation of cytoskeletal organization (phalloidin), particularly

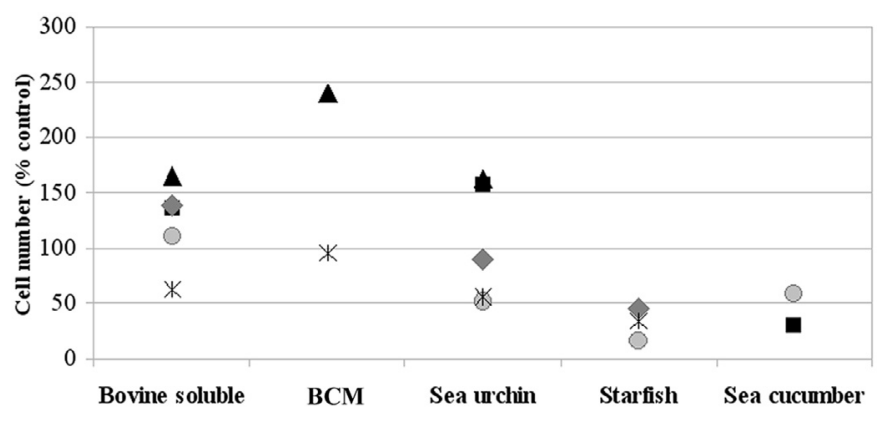

Substrate

Fig. 7. Cell counting after 4 days of culture of human skin-derived fibroblasts seeded on bovine skin-derived soluble collagen, reassembled (fibrillar) bovine collagen membranes (BCMs) and EDCMs normalized against the plastic control (100\%). Data shown as mean values of 2-4 replicates (see Table A in Appendices for mean values \pm SD for each round). Black square: first round; grey diamond: second round; grey circle: third round; black triangle: fourth round; asterisk: fifth round.

stress fibres, contractile actin bundles fundamental for cell adhesion. Fibroblasts seeded on fibrillar substrates (namely EDCMs and BCMs) showed less stress fibres and less numerous focal adhesion plaques (vinculin) comparing to those on "flat" substrates. Fig. 10 shows two representative examples (plastic and sea cucumberderived membrane) of the aforementioned differences.

\section{Discussion}

Marine collagen is one of the most promising biomaterials for a wide range of different applications (Silva et al., 2014; Silvipriya et al., 2015). New biotechnology with a low environmental impact are nowadays widely encouraged since the large public attention and sensibility to both human health and eco-sustainable nature exploitation have highly increased in the last few decades. Many marine animals are currently investigated and used to extract collagen (Nagai and Suzuki, 2000; Nagai et al., 2000; UriarteMontoya et al., 2010; Addad et al., 2011; Pang et al., 2013). Echinoderms especially can be valid "blue" and alternative sources of collagen to the currently used mammalian ones. Indeed, as previously described by Di Benedetto et al. (2014), fibrillar collagen can be easily extracted from echinoderm MCTs and the high plasticity of their collagen fibril cohesive forces/cross-linking (Wilkie, 2005) is probably one of the reasons for the relative ease with which collagen fibrils can be isolated.

In the present work we optimized different extraction protocols to efficiently obtain clean, relatively pure and highly concentrated native collagen fibril suspensions from three echinoderm MCTs/ species, which differ in the overall collagen fibril and fibre organization and in the skeletal element presence (Fig. 1). Starfish aboral arm wall and partly sea urchin peristomial membrane show highly packed fibrils/fibres and conspicuous calcareous ossicles, whereas sea cucumber body wall displays loosely packed and homogeneously widespread fibrils as well as small calcareous spicules. This can partially explain why fibril extraction is easily obtained by mild non-denaturing methods (such as PBS) for sea cucumber, whereas stronger treatments (disulphide bonds disruption) are necessary for both sea urchin and starfish. Despite these differences, the fibrillar conformation and integrity were maintained throughout the extraction protocols, an important feature for the subsequent employment in scaffolding. Indeed, it is well-documented that the reassembling of mammalian solubilized collagen (by simple $\mathrm{pH} /$ temperature variation or electrospinning) produces fibrillar structures which are only partially similar to the 

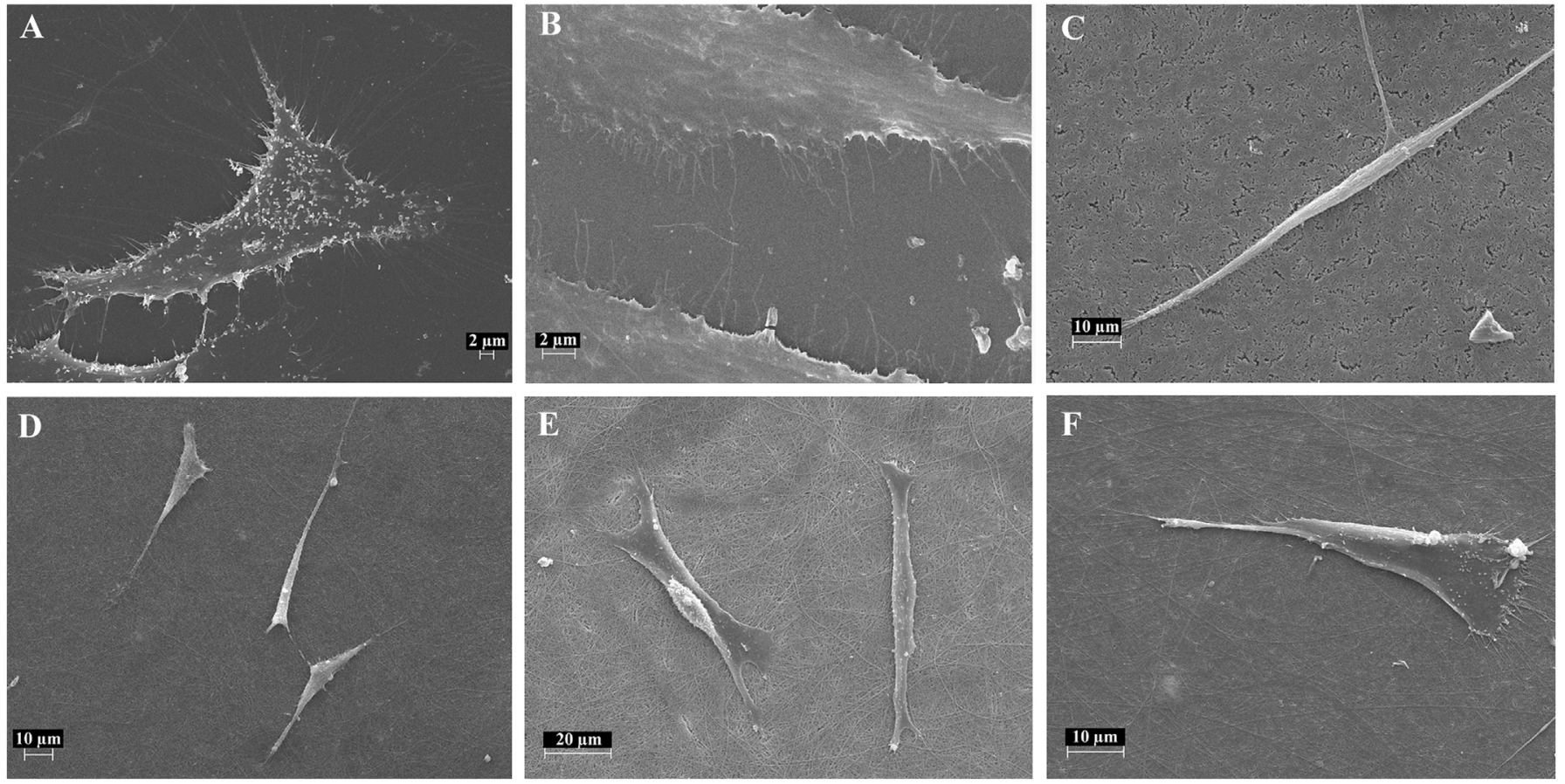

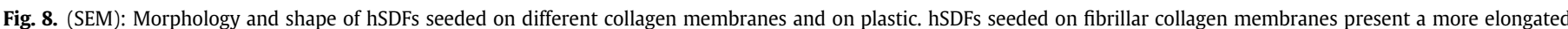

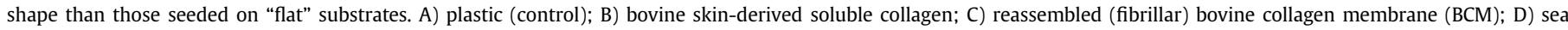
urchin-derived collagen membrane; E) starfish-derived collagen membrane; F) sea cucumber-derived collagen membrane.
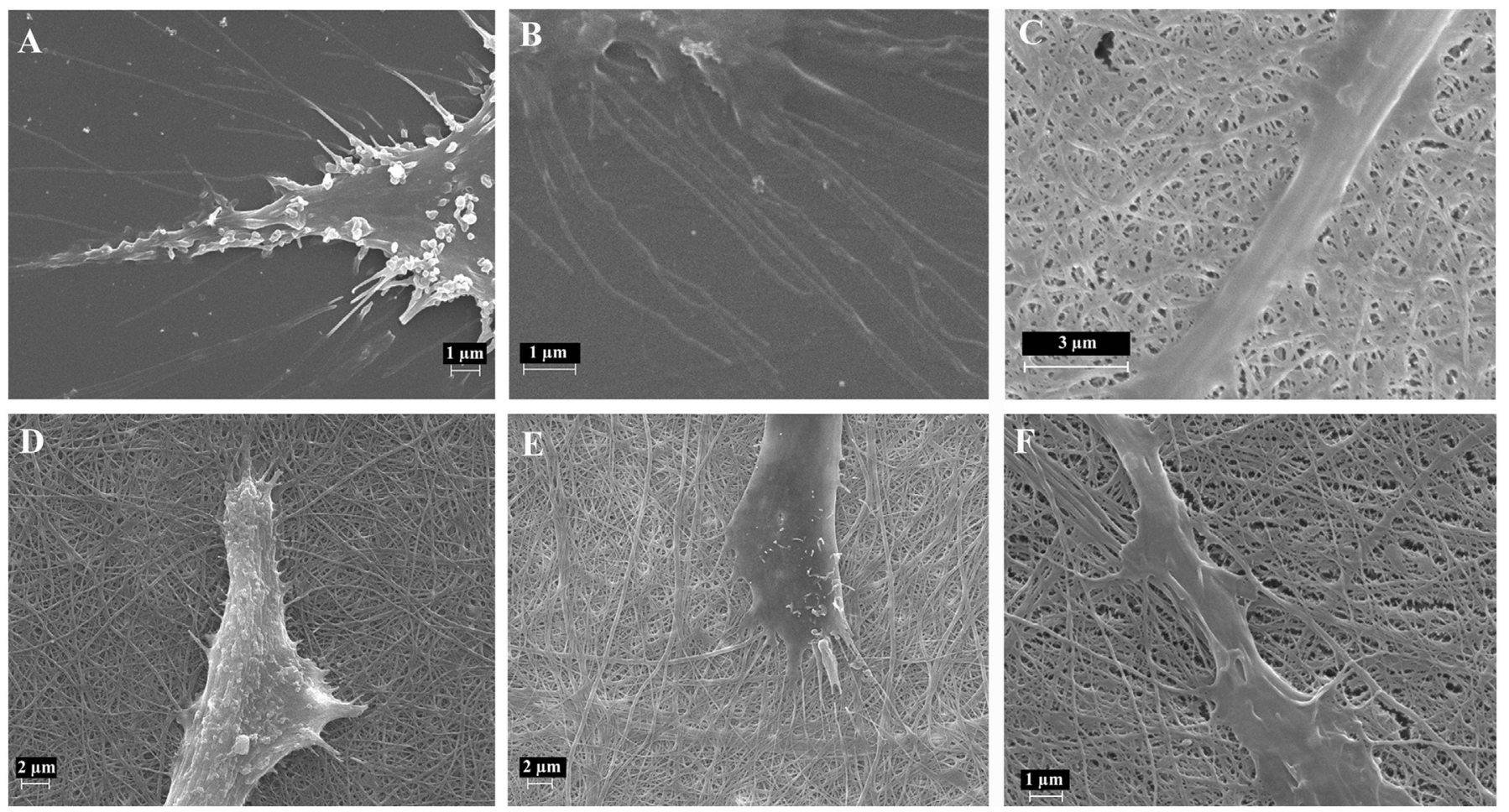

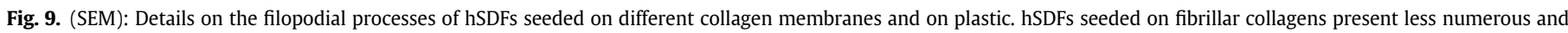

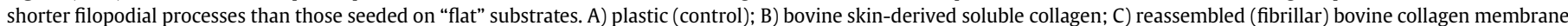
(BCM); D) sea urchin-derived collagen membrane; E) starfish-derived collagen membrane; F) sea cucumber-derived collagen membrane.

native conformation in terms of both mechanical and structural properties (Zeugolis et al., 2008; Chung et al., 2010). Also collagens from other marine sources, e.g. fish, jellyfish and sponges, are currently extracted in their acid-soluble form, thus losing their native conformation (Nagai and Suzuki, 2000; Addad et al., 2011; Barros et al., 2014). 

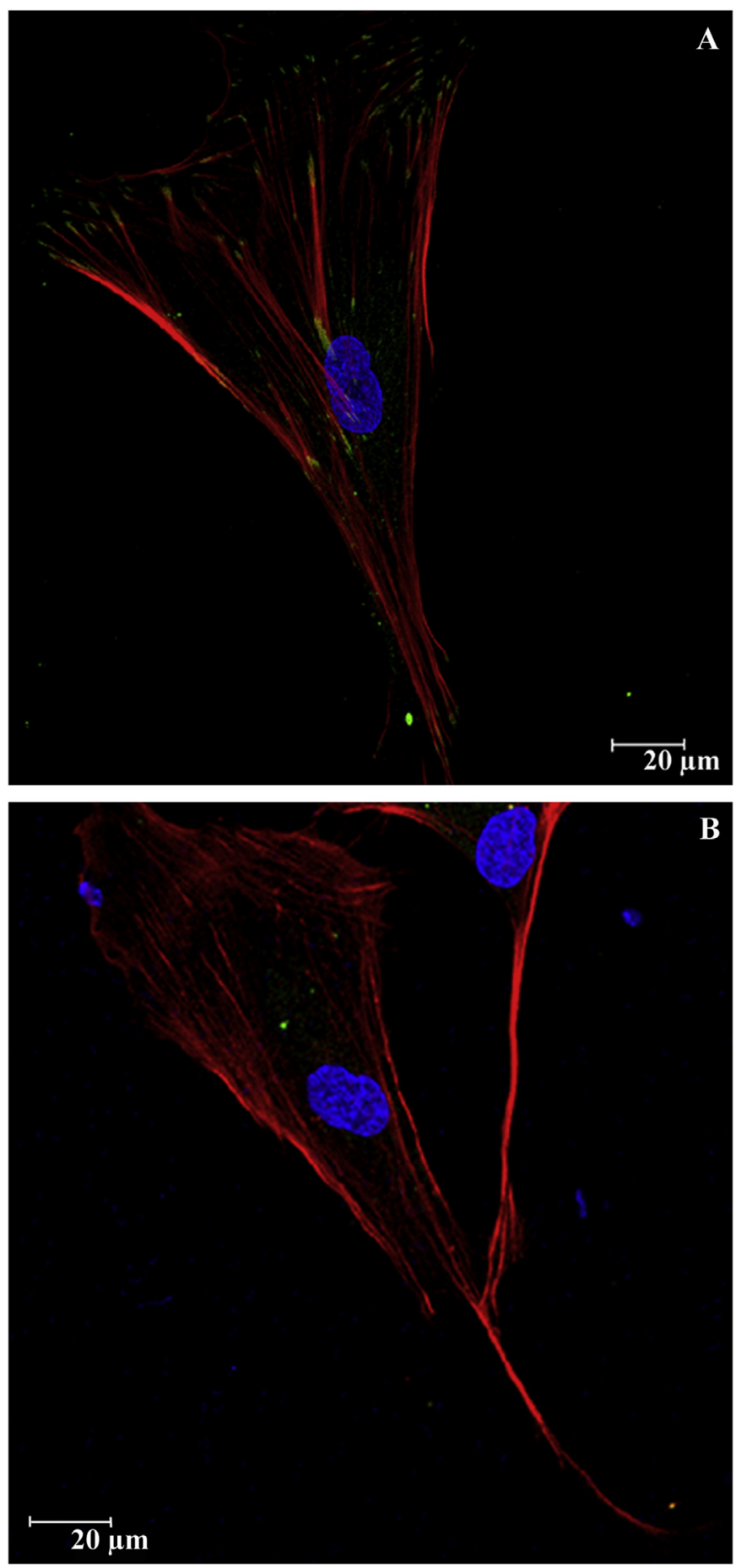

Fig. 10. (IF): Representative images of the morphology, cytoskeletal (F-actin) organization and focal adhesion plaque pattern of hSDFs seeded on "flat" substrate (A) and fibrillar substrate (B). Cell nuclei are labelled in blue (DAPI), stress fibres in red (phalloidin) and focal adhesion plaques in green (vinculin). hSDFs seeded on fibrillar substrate present less numerous stress fibres and less visible focal adhesion plaques in comparison to those seeded on "flat" substrate.

Fibril mean diameter and D-period were similar among the three types of echinoderm sources and comparable also to those reported for other MCTs (Barbaglio et al., 2015), other marine animals (Heinemann et al., 2007) and mammalian type I collagen (Gelse et al., 2003; Wilkie, 2005; Fang and Holl, 2013).
Glycosaminoglycan (GAG) presence along the fibril surface is fundamental to maintain fibril integrity (Tricarico et al., 2012). Moreover, GAGs are important for cell migration, adhesion, proliferation and differentiation (Pieper et al., 2000) both in vitro (e.g. cell culture) and in vivo (e.g. morphogenesis and wound healing) and are often added to mammalian collagen scaffolds to improve their performances in tissue engineering applications (Haugh et al., 2011). Therefore, obtaining a native fibrillar collagen already provided with GAG decoration is one of the advantages of EDCMs.

The average superficial porosity of EDCMs was much smaller than the size of human cells. Therefore, they are likely to be efficient as cell barrier for biomedical applications where a proper division between two anatomical compartments is requested, such as Guided Tissue Regeneration (GTR). In GTR these barriers help the healing process avoiding mixture of adjacent regenerating tissues and are useful to prevent post-surgical tissue adhesions (Tsai et al., 2005). These latter are widespread and serious medical problems, not only for the patient health (Diamond and Freeman, 2001) but also from an economic point of view (Wilson et al., 2002). Commercial bovine collagen membranes are currently used for this kind of purposes (Fig. 4). However, their porosity is much higher and their network is less homogeneous than those of EDCMs (Table 1; Fig. 2), thus suggesting these latter are likely to display a more efficient barrier-effect.

EDCM limited thickness, combined with high mechanical resistance, can be further advantages since this biomaterial simultaneously provides handleability during surgery, reduced steric hindrance in the wound and post-surgery resistance to avoid dehiscence occurrence: the higher the tensile strength and the resistance to uni-axial tension (Young's Modulus) the better the biomaterial can support stresses before rupture. The mechanical resistance of commercial membranes (Figs. 5 and 6), which display a much higher thickness, or reported for bovine-derived collagen membranes cross-linked with EDC/NHS ( 30 MPa; Grover et al., 2012) is much lower compared to EDCMs, thus suggesting the potential utility of echinoderm collagens, especially in mechanically demanding tissue engineering applications. Lower values of EDCM tensile strain (relative elongation) than those recorded for commercial membranes further support the previous statement. Moreover, the possibility to produce much thinner membranes is an obvious advantage also from a practical point of view since a lower amount of fresh material is necessary.

Having highlighted the advantages of EDCMs, is there a favoured echinoderm/MCT collagen source for the proposed application? Despite the comparable ultrastructural characteristics and mechanical performances (with sea cucumber membranes displaying slightly higher values), the three different EDCMs showed partially different results in the in vitro tests with human skin-derived fibroblasts. We previously demonstrated that sea urchin-derived membranes are not toxic for mammalian cells: horse mesenchymal stem cells seeded on these substrates were viable and even able to actively proliferate in long-term period (21 days), although they showed an initial transitory "drop" (day 4) and a slight delay compared to controls (Di Benedetto et al., 2014).

In this work we used human adult fibroblasts because this cytotype is the most suitable in view of GTR applications and because it was largely used to test also different marine-derived collagen substrates, such as from jellyfish (Song et al., 2006; Addad et al., 2011). Cells seeded on EDCMs and BCMs (both regarded as fibrillar substrates) were similar in terms of morphology, cytoskeletal organization and substrate adhesion pattern, thus suggesting the absence of any anomalous cell behaviour due to the echinoderm-derived collagen. Interestingly, they presented a more elongated shape, less and shorter filopodial processes in comparison with those seeded on "flat" substrates (bovine skin-derived 
soluble collagen and plastic), possibly indicating a reduced substrate adhesion, a feature that can be advantageous in "cell barrier" for GTR applications. Nevertheless, cell numbers recorded after 4 days were different on the three EDCMs: sea urchin membranes displayed similar values to bovine collagen substrates and to plastic control, whereas both starfish and sea cucumber membranes showed a lower number. Whether this is only a transient and temporary cell behaviour, as we previously observed for sea urchin membranes (Di Benedetto et al., 2014) or it's a toxic effect must be investigated by further long-term analyses. In general, our findings underline also that the standard controls usually employed for this kind of in vitro tests (soluble collagen and plastic) are not truly reliable to test biocompatibility of fibrillar substrates, as they display a different structure/geometry ("flat" $v s$ fibrillar), a parameter strongly influencing cell behaviour and response (Murphy et al., 2012).

From a socio-economical perspective, sea urchins, and partially starfish, might display a major advantage if compared to sea cucumbers. In the former, collagen can be reliably obtained as food industry by-product without affecting natural populations. In starfish, high amount of eco-friendly collagen could be obtained from those ecologically "dangerous" species regularly subjected to massive control campaigns (e.g. the coral feeder crown-of-thorn Acanthaster planci; Fraser et al., 2000; Mendonça et al., 2010; Baird et al., 2013). Sea cucumbers, from both fishery and aquaculture (Toral-Granda et al., 2008; Purcell et al., 2013; Yokoyama, 2013), have the undoubted advantage of the amount of collagen obtainable from a single animal but are over exploited as source of food, especially in the Asian cuisine and, therefore, they could not be conveniently used as by-product. Thus, in terms of ecosustainability sea urchins and starfish should be preferred to sea cucumbers. However, considering a possible industrial scale-up, at present sea urchin employment seems more promising and feasible. The increased market demand and the simultaneous decline of sea urchin wild populations all over the world are making aquaculture a fundamental alternative to sea urchin fishery (Carboni et al., 2012; Parisi et al., 2012). The possibility to valorise sea urchin by-product is likely to further promote the development of this mariculture sector. Moreover, sea urchin farming in (environmentally sustainable) integrated multi-trophic aquacultures (IMTA) will also ensure social acceptance and additional economic advantages (Schuenhoff et al., 2003; Barrington et al., 2009). interesting in terms of both research and applied studies. We propose this "blue" biomaterial derived from marine invertebrates, especially from sea urchins, as a promising alternative to the nowadays mammalian-derived collagen biomaterials. Further in vitro and in vivo studies are necessary to more deeply evaluate EDCM exploitability, including permeability, biodegradability and immunogenicity, all of these being key features to validate new biomaterials for human clinical applications (Chung et al., 1990).

\section{Conflict of interest disclosure}

The authors certify that there is no conflict of interest. All authors contributed to and approved the final manuscript.

\section{Authors' contributions}

CF, MS and CAMLP conceived the study. CF and MS wrote the manuscript. LL and CDB collected the experimental animals. CF, LL, RL, CDB and LG carried out the experiments. CF and MS analysed the data. MA helped with immunofluorescence microscopy analyses. VC provided human skin-derived fibroblasts. FB, CAMLP, MDCC and MS contributed with reagents, materials and analyses.

\section{Acknowledgements}

This research was funded by Young Researcher Grant (University of Milan, PI: Dr. Michela Sugni). We are grateful to the Marine Protected Area of Portofino (GE, Italy) for permission to collect experimental animals and to the scuba diver Dr. Dario Fassini for helping during the collection. We would like to deeply thank Dr. Paolo Tremolada for his support with statistical analyses, Andrea Spalletti and Silvia Colombo for helping in cell culture experiments, Prof. Iain Wilkie for mechanical equipment use and Dr. Dario Fassini for welcome comments on mechanical tests. We also thank Dr. Elena Canciani for providing commercial membranes used in this work.

\section{Appendices}

Table A

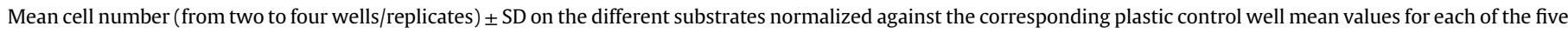

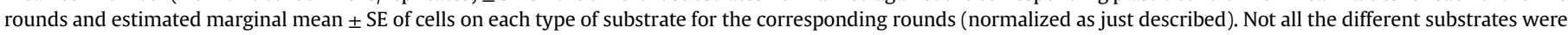
present in each round due to starting material availability.

\begin{tabular}{|c|c|c|c|c|c|}
\hline & $\begin{array}{l}\text { Bovine skin-derived soluble } \\
\text { collagen substrate }\end{array}$ & $\begin{array}{l}\text { Reassembled (fibrillar) bovine } \\
\text { collagen membrane (BCM) }\end{array}$ & $\begin{array}{l}\text { Sea urchin-derived } \\
\text { collagen membrane }\end{array}$ & $\begin{array}{l}\text { Starfish-derived } \\
\text { collagen membrane }\end{array}$ & $\begin{array}{l}\text { Sea cucumber-derived } \\
\text { collagen membrane }\end{array}$ \\
\hline Round 1 & $136.19 \pm 18.58$ & - & $156.17 \pm 16.50$ & - & $29.73 \pm 2.16$ \\
\hline Round 2 & $139.73 \pm 18.62$ & - & $90.60 \pm 7.67$ & $45.66 \pm 9.75$ & - \\
\hline Round 3 & $109.97 \pm 10.71$ & - & $51.41 \pm 6.33$ & $16.61 \pm 4.70$ & $58.17 \pm 15.93$ \\
\hline Round 4 & $165.21 \pm 85.48$ & $240.17 \pm 148.25$ & $161.97 \pm 13.31$ & - & - \\
\hline Round 5 & $62.51 \pm 9.18$ & $96.07 \pm 18.13$ & $55.29 \pm 3.94$ & $34.60 \pm 5.82$ & - \\
\hline $\begin{array}{l}\text { Estimated marginal } \\
\text { mean } \pm \mathrm{SE}\end{array}$ & $122.73 \pm 10.33$ & $168.12 \pm 14.91$ & $103.09 \pm 8.44$ & $32.29 \pm 13.55$ & $43.95 \pm 17.83$ \\
\hline
\end{tabular}

\section{Conclusions}

Echinoderm MCTs can be considered eco-sustainable sources of fibrillar collagen for biomedical applications. The possibility to rapidly produce valuable collagen membranes suitable for specific clinical purposes makes these marine invertebrates highly

\section{References}

Addad, S., Exposito, J.Y., Faye, C., Ricard-Blum, S., Lethias, C., 2011. Isolation, characterization and biological evaluation of jellyfish collagen for use in biomedica applications. Mar. Drugs 9, 967-983. http://dx.doi.org/10.3390/md9060967.

Baird, A.H., Pratchett, M.S., Hoey, A.S., Herdiana, Y., Campbell, S.J., 2013. Acanthaster planci is a major cause of coral mortality in Indonesia. Coral Reefs 32, 803-812. 
http://dx.doi.org/10.1007/s00338-013-1025-1.

Barbaglio, A., Tricarico, S., Ribeiro, A., Ribeiro, C., Sugni, M., Di Benedetto, C. Wilkie, I.C., Barbosa, M., Bonasoro, F., Candia Carnevali, M.D., 2012. The mechanically adaptive connective tissue of echinoderms: its potential for bioinnovation in applied technology and ecology. Mar. Environ. Res. - Special Issue Mar. Org. 76, 108-113, http://dx.doi.org/10.1016/j.marenvres.2011.07.006.

Barbaglio, A., Tricarico, S., Di Benedetto, C., Fassini, D., Lima, A.P., Ribeiro, A.R Ribeiro, C.C., Sugni, M., Bonasoro, F., Wilkie, I.C., Barbosa, M., Candia Carnevali, M.D., 2013. The smart connective tissue of echinoderms: a materializing promise for biotech applications. Cah. Biol. Mar. 54, 713-720.

Barbaglio, A., Tricarico, S., Ribeiro, A., Di Benedetto, C., Barbato, M., Dessì, D. Fugnanesi, V., Magni, S., Mosca, F., Sugni, M., Bonasoro, F., Wilkie, I.C., Barbosa, M., Candia Carnevali, M.D., 2015. Ultrastructural and biochemical characterization of mechanically adaptable collagenous structures in the edible sea urchin Paracentrotus lividus. Zoology 118, 147-160. http://dx.doi.org/ 10.1016/j.zool.2014.10.003.

Barrington, K., Chopin, T., Robinson, S., 2009. Integrated multi-trophic aquaculture (IMTA) in marine temperate waters. In: Soto, D. (Ed.), Integrated Mariculture: Global Review. FAO Fisheries and Aquaculture Technical Paper. No. 529. Rome, FAO, pp. 7-46.

Barros, A.A., Aroso, I.M., Silva, T.H., Mano, J.F., Duarte, A.R.C., Reis, R.L., 2014. Water and carbon dioxide: green Solvents for the extraction of collagen/gelatin from marine sponges. ACS Sustain. Chem. Eng. 3, 254-260. http://dx.doi.org/10.1021/ sc500621z.

Baumiller, T.K., Ausich, W.I., 1996. Crinoid stalk flexibility: theoretical predictions and fossil stalk postures. Lethaia 29, 47-59. Oslo. ISSN 0024-1 164.

Buck II, D.V., Alam, M., Kim, J.Y.S., 2009. Injectable fillers for facial rejuvenation: review. J. Plastic Reconstr. Aesthet. Surg. 62, 11-18. http://dx.doi.org/10.1016 j.bjps.2008.06.036.

Carboni, S., Addis, P., Cau, A., Atack, T., 2012. Aquaculture could enhance Mediterranean Sea urchin fishery, expand supply. Glob. Aquac. Advocate (Issue May/ June), 44-45.

Chung, K.M., Salkin, L.M., Stein, M.D., Freedma, A.L., 1990. Clinical evaluation of a biodegradable collagen membrane in guided tissue regeneration. J. Periodontology 61 (12), 732-736. http://dx.doi.org/10.1902/ jop.1990.61.12.732.

Chung, K.H., Bhadriraju, K., Spurlin, T.A., Cook, R.F., Plant, A.L., 2010. Nanomechanical properties of thin films of type I collagen fibrils. Langmuir 26, 3629-3636. http://dx.doi.org/10.1021/la903073v.

Coccè, V., Vitale, A., Colombo, S., Bonomi, A., Sisto, F., Ciusani, E., Alessandri, G. Parati, E. Brambilla, P. Brambilla, M., La Porta, C.A.M. Pessina, A. 2016. Human skin derived fibroblasts as trojan horse of drug delivery. Clin. Exp. Dermatol. http://dx.doi.org/10.1111/ced.12811.

Conand, C., 2004. Present status of world sea cucumber resources and utilization: an international overview: 13-23. In: Lovatelli, A., Conand, C., Purcell, S. Uthicke, S., Hamel, J.F., Mercier, A. (Eds.), Advances in Sea Cucumber Aquaculture and Management, p. 425. FAO Fisheries Technical Paper. No. 463. Rome FAO.

Dembitsky, V.M., Gloriozova, T.A., Poroikov, V.V., 2005. Novel antitumor agents: marine sponge alkaloids, their synthetic analogs and derivatives. Mini Rev. Med. Chem. 5, 319-336.

Diamond, M.P., Freeman, M.L., 2001. Clinical implications of postsurgical adhesions Hum. Reprod. Update 7, 567-576.

Di Benedetto, C., Barbaglio, A., Martinello, T., Alongi, V., Fassini, D., Cullorà, E Patruno, M., Bonasoro, F., Barbosa, M.A., Candia Carnevali, M.D., Sugni, M., 2014 Production, characterization and biocompatibility of marine collagen matrices from an alternative and sustainable source: the sea urchin Paracentrotus lividus. Mar. Drugs 12, 4912-4933. http://dx.doi.org/10.3390/md12094912.

Djagny, K.B., Wang, Z., Xu, S., 2010. Gelatin: a valuable protein for food and pharmaceutical industries: review. Crit. Rev. Food Sci. Nutr. 41 (6), 481-492. http:/ dx.doi.org/10.1080/20014091091904.

European Commission, 2012. Blue Growth: Opportunities for Marine and Maritime Sustainable Growth. Communication from the Commission to the European Parliament, the Council, the European Economic and Social Committee and the Committee of the Regions. Publications Office of the European Union, Luxembourg. http://dx.doi.org/10.2771/43949. ISBN 978-92-79-25529-8.

Fang, M., Holl, M.M.B., 2013. Variation in type I collagen fibril nanomorphology: the significance and origin. BoneKEy Rep. 2, 394. http://dx.doi.org/10.1038/ bonekey.2013.128.

Ferreira, A.M., Gentile, P., Chiono, V., Ciardelli, G., 2012. Collagen for bone tissue regeneration. Acta Biomater. 8, 3191-3200. http://dx.doi.org/10.1016/ j.actbio.2012.06.014.

Fraser, N., Crawford, B., Kusen, J., 2000. Best Practices Guide for Crown-of-thorns Clean-ups. Proyek Pesisir Special Publication. Coastal Resources Center Coastal Management Report \#2225. Coastal Resources Center, University of Rhode Island, Narragansett, Rhode Island, p. 38.

Gelse, K., Poschl, E., Aigner, T., 2003. Collagens-Structure, function, and biosynthesis Adv. Drug Deliv. Rev. 55, 1531-1546. http://dx.doi.org/10.1016 addr.2003.08.002.

Glowacki, J., Mizuno, S., 2008. Collagen scaffolds for tissue engineering. Biopolymers 89 (5), 338-344. http://dx.doi.org/10.1002/bip.20871.

Gomez d'Ayala, G., Malinconico, M., Laurienzo, P., 2008. Marine derived polysaccharides for biomedical applications: chemical modification approaches. Molecules 13, 2069-2106. http://dx.doi.org/10.3390/molecules13092069.

Gómez-Guillén, M.C., Giménez, B., López-Caballero, M.E., Montero, M.P., 2011
Functional and bioactive properties of collagen and gelatin from alternative sources: a review. Food Hydrocoll. 25, 1813-1827. http://dx.doi.org/10.1016 j.foodhyd.2011.02.007.

Grover, C.N., Gwynne, J.H., Pugh, N., Hamaia, S., Farndale, R.W., Best, S.M., Cameron, R.E., 2012. Crosslinking and composition influence the surface properties, mechanical stiffness and cell reactivity of collagen-based films. Acta Biomater. 8, 3080-3090. http://dx.doi.org/10.1016/j.actbio.2012.05.006.

Gupta, S., Abu-Ghannam, N., 2011. Bioactive potential and possible health effects of edible brown seaweeds. Trends Food Sci. Technol. 22, 315-326.

Guzmán, E.A., Johnson, J.D., Linley, P.A., Gunasekera, S.E., Wright, A.E., 2011. A novel activity from an old compound: Manzamine A reduces the metastatic potential of AsPC-1 pancreatic cancer cells and sensitizes them to TRAIL-induced apoptosis. J. New Anticancer Agents 29, 777-785.

Haugh, M.G., Murphy, C.M., McKiernan, R.C., Altenbuchner, C., O'Brien, F.J., 2011. Crosslinking and mechanical properties significantly influence cell attachment, proliferation, and migration within collagen glycosaminoglycan scaffolds. Tissue Eng. A 17, 1201-1208. http://dx.doi.org/10.1089/ten.tea.2010.0590.

Heinemann, S., Ehrlich, H., Douglas, T., Heinemann, C., Worch, H., Schatton, W., Hanke, T., 2007. Ultrastructural studies on the collagen of the marine sponge Chondrosia reniformis Nardo. Biomacromolecules 8, 3452-3457.

Jenkins, E.D., Yip, M., Melman, L., Frisella, M.M., Matthews, B.D., 2010. Informed consent: cultural and religious issues associated with the use of allogeneic and xenogeneic mesh products. J. Am. Coll. Surg. 210 (4), 402-410. http:// dx.doi.org/10.1016/j.jamcollsurg.2009.12.001.

Karim, A.A., Bhat, R., 2008. Gelatin alternatives for the food industry: recent developments, challenges and prospects. Trends Food Sci. Technol. 19, 644-656.

Kew, S.J., Gwynne, J.H., Enea, D., Abu-Rub, M., Pandit, A., Zeugolis, D., Brooks, R.A., Rushton, N., Best, S.M., Cameron, R.E., 2011. Regeneration and repair of tendon and ligament tissue using collagen fibre biomaterials. Acta Biomater. 7, 3237-3247. http://dx.doi.org/10.1016/j.actbio.2011.06.002.

Lee, J., Cuddihy, M.J., Kotov, N.A., 2008. Three-dimensional cell culture matrices: state of the art. Tissue Eng. B 14 (1), 61-86. http://dx.doi.org/10.1089/ teb.2007.0150

Matsumura, T., 1974. Collagen fibrils of the sea cucumber, Stichopus japonicus: purification and morphological study. Connect. Tissue Res. 2, 117-125.

Mendonça, V.M., Al Jabri, M.M., Al Ajmi, I., Al Muharrami, M., Al Areimi, M., Al Aghbari, H.A., 2010. Persistent and Expanding population outbreaks of the corallivorous starfish Acanthaster planci in the Northwestern indian ocean: are they really a consequence of unsustainable starfish predator removal through overfishing in coral reefs, or a response to a changing environment? Zool. Stud. 49 (1), 108-123.

Murphy, C.M., Matsiko, A., Haugh, M.G., Gleeson, J.P., O'Brien, F.J., 2012. Mesenchymal stem cell fate is regulated by the composition and mechanical properties of collagen-glycosaminoglycan scaffolds. J. Mech. Behav. Biomed. 11, $53-62$.

Nagai, T., Suzuki, N., 2000. Isolation of collagen from fish waste material-skin, bone and fins. Food Chem. 68, 277-281.

Nagai, T., Worawattanamateekul, W., Suzuki, N., Nakamura, T., Ito, T., Fujiki, K. Nakao, M., Yano, T., 2000. Isolation and characterization of collagen from rhizostomous jellyfish (Rhopilema asamushi). Food Chem. 70, 205-208.

Pang, S., Chang, Y.P., Woo, K.K., 2013. The evaluation of the suitability of fish wastes as a source of collagen. In: 2nd International Conference on Nutrition and Food Sciences IPCBEE, vol. 53. IACSIT Press, Singapore. http://dx.doi.org/10.7763/ IPCBEE. 2013. V53. 15.

Parisi, G., Centoducati, G., Gasco, L., Gatta, P.P., Moretti, V.M., Piccolo, G., Roncarati, A., Terova, G., Pais, A., 2012. Molluscs and echinoderms aquaculture: biological aspects, current status, technical progress and future perspectives for the most promising species in Italy. Italian J. Animal Sci. 11, e72. http:// dx.doi.org/10.4081/ijas.2012.e72.

Parker, M.C., Ellis, H., Moran, B.J., Thompson, J.N., Wilson, M.S., Menzies, D., McGuire, A., Lower, A.M., Hawthorn, R.J.S., O'Brien, F., Buchan, S., Crowe, A.M. 2001. Postoperative adhesions: ten-year follow-up of 12,584 patients undergoing lower abdominal surgery. Dis. Colon Rectum 44 (6), 822-829.

Pieper, J.S., van Wachem, P.B., van Luyn, M.J.A., Brouwer, L.A., Hafmans, T., Veerkamp, J.H., van Kuppevelt, T.H., 2000. Attachment of glycosaminoglycans to collagenous matrices modulates the tissue response in rats. Biomaterials 21 (16), 1689-1699. http://dx.doi.org/10.1016/S0142-9612(00)00052-1.

Purcell, S.W., Mercier, A., Conand, C., Hamel, J.F., Toral-Granda, M.V., Lovatelli, A., Uthicke, S., 2013. Sea cucumber fisheries: global analysis of stocks, management measures and drivers of overfishing. Fish Fish. 14, 34-59. http://dx.doi.org/ 10.1111/j.1467-2979.2011.00443.x.

Rao, K.V., Donia, M.S., Peng, J., Garcia, E.P., Alonso, D., Martinez, A., Medina, M., Franzblau, S.G., Tekwani, B.L., Khan, S.I., Wahyuono, S., Willett, K.L., Hamann, M.T., 2006. Manzamine B and E and ircinal a related alkaloids from an Indonesian Acanthostrongylophora sponge and their activity against infectious, tropical parasitic, and Alzheimer's diseases. J. Nat. Prod. 69 (7), 1034-1040.

Ruszczak, Z., 2003. Effect of collagen matrices on dermal wound healing. Adv. Drug Deliv. Rev. 55, 1595-1611. http://dx.doi.org/10.1016/j.addr.2003.08.003.

Sahithi, B., Ansari, S.K., Hameeda, S.K., Sahithya, G., Durga Prasad, M., Yogitha, L., 2013. A review on collagen based drug delivery systems. Indian J. Res. Pharm. Biotechnol. 1 (3), 461-468.

Schuenhoff, A., Shpigelb, M., Lupatschb, I., Ashkenazi, A., Msuya, F.E., Neori, A., 2003. A semi-recirculating, integrated system for the culture of fish and seaweed. Aquaculture 221, 167-181. http://dx.doi.org/10.1016/S0044-8486(02)00527-6. Shimomura, O., Johnson, F.H., Saiga, Y., 1962. Extraction, purification and properties 
of aequorin, a bioluminescent protein from the luminous hydromedusan, Aequorea. J. Cell Comp. Physiol. 59, 223-239.

Silva, T.H., Moreira-Silva, J., Marques, A.L.P., Domingues, A., Bayon, Y., Reis, R.L., 2014. Marine origin collagens and its potential applications. Mar. Drugs 12, 5881-5901. http://dx.doi.org/10.3390/md12125881.

Silvipriya, K.S., Kumar, K.K., Bhat, A.R., Kumar, B.D., John, A., lakshmanan, P., 2015. Collagen: animal sources and biomedical application. J. Appl. Pharm. Sci. 5 (03), 123-127. http://dx.doi.org/10.7324/JAPS.2015.50322.

Song, E., Yeon Kim, S., Chun, T., Byun, H.Y., Lee, Y.M., 2006. Collagen scaffolds derived from a marine source and their biocompatibility. Biomaterials 27, 2951-2961. http://dx.doi.org/10.1016/j.biomaterials.2006.01.015.

Swatschek, D., Schatton, W., Kellermann, J., Müller, W.E.G., Kreuter, J., 2002. Marine sponge collagen: isolation, characterization and effects on the skin parameters surface-pH, moisture and sebum. Eur. J. Pharm. Biopharm. 53, 107-113.

Tal, H., Moses, O., Kozlovsky, A., Nemcovsky, C., 2012. In: Tal, Haim (Ed.), Bioresorbable Collagen Membranes for Guided Bone Regeneration, Bone Regeneration. ISBN: 978-953-51-0487-2. InTech.

Tang, S., Yang, W., Mao, X., 2007. Agarose/collagen composite scaffold as an antiadhesive sheet. Biomed. Mater. 2, S129-S134. http://dx.doi.org/10.1088/1748$6041 / 2 / 3 /$ S09.

Toral-Granda, V., Lovatelli, A., Vasconcellos, M., 2008. Sea Cucumbers: a Global Review of Fisheries and Trade. FAO fisheries and aquaculture technical paper 516. ISBN 978-92-5-106079-7.

Tricarico, S., Barbaglio, A., Burlini, N., Del Giacco, L., Ghilardi, A., Sugni, M., Di Benedetto, C., Bonasoro, F., Wilkie, I.C., Candia Carnevali, M.D., 2012. New insights into the mutable collagenous tissue of Paracentrotus lividus: preliminary results. Zoosymposia 7, 279-285.
Trotter, J.A., Thurmond, F.A., Koob, T.J., 1994. Molecular structure and functional morphology of echinoderm collagen fibrils. Cell Tissue Res. 275, 451-458.

Tsai, S.W., Fang, J.F., Yang, C.L., Chen, J.H., Su, L.T., Jan, S.H., 2005. Preparation and evaluation of a hyaluronate-collagen film for preventing post-surgical adhesion. J. Int. Med. Res. 33, 68-76.

Uriarte-Montoya, M.H., Arias-Moscoso, J.L., Plascencia-Jatomea, M., SantacruzOrtega, H., Rouzaud-Sández, O., Cardenas-Lopez, J.L., Marquez-Rios, E., Ezquerra-Brauer, J.M., 2010. Jumbo squid (Dosidicus gigas) mantle collagen: extraction, characterization, and potential application in the preparation of chitosan-collagen biofilms. Bioresour. Technol. 101, 4212-4219. http:// dx.doi.org/10.1016/j.biortech.2010.01.008.

Wilkie, I.C., 2005. Mutable collagenous tissue: overview and perspectives. In: Matranga, V. (Ed.), Echinodermata. Progress in Molecular and Subcellular Biology. Marine Molecular Biotechnology, vol. 5. Springer, Berlin, pp. 221-250.

Wilson, M.S., Menzies, D., Knight, A., Crowe, A.M., 2002. Demonstrating the clinical and cost effectiveness of adhesion reduction strategies. Colorectal Dis. 4 355-360.

Yang, C.R., 2012. Enhanced physicochemical properties of collagen by using EDC NHS-crosslinking. Bull. Mater. Sci. 35, 913-918.

Yokoyama, H., 2013. Growth and food source of the sea cucumber Apostichopus japonicus cultured below fish cages - potential for integrated multi-trophic aquaculture. Aquaculture 372-375, 28-38. http://dx.doi.org/10.1016 j.aquaculture.2012.10.022.

Zeugolis, D.I., Khew, S.T., Yew, E.S.Y., Ekaputra, A.K., Tong, Y.W., Yung, L.Y.L. Hutmacher, D.W., Sheppard, C., Raghunath, M., 2008. Electro-spinning of pure collagen nano-fibrese - just an expensive way to make gelatin? Biomaterials 29, 2293-2305. http://dx.doi.org/10.1016/j.biomaterials.2008.02.009. 